\title{
O TRABALHO DO ENFERMEIRO NOS CENTROS DE ATENÇÃO PSICOSSOCIAL
}

THE WORK OF THE NURSE IN PSYCHOSOCIAL CARE CENTERS

Luciane Prado Kantorski ${ }^{1}$

Fernanda Barreto Mielke ${ }^{2}$

Sidnei Teixeira Júnior ${ }^{3}$

Resumo Este estudo trata do perfil e atividades desenvolvidas por enfermeiros nos centros de atenção psicossocial (Caps). Consiste num estudo qualitativo do tipo descritivo. O instrumento de pesquisa utilizado foi a entrevista estruturada, realizada com 13 enfermeiros dos Caps I e II, pertencentes à área de abrangência da Terceira Coordenadoria Regional de Saúde do Rio Grande do Sul ( $3^{\mathrm{a}} \mathrm{CRS} / \mathrm{RS}$ ), onde foram apreendidas informações sobre a clientela atendida no serviço, composição da equipe, atividades realizadas e ações desenvolvidas pelo enfermeiro no Caps. Os enfermeiros elencaram suas atividades na prática cotidiana do Caps e estas foram contextualizadas a partir do referencial da reabilitação psicossocial no interior da reforma psiquiátrica.

Palavras-chave trabalho; enfermagem; saúde mental.
Abstract This study concerns the profile and activities carried out by nurses in the Psychosocial Care Centers (Caps). It is a qualitative study of the descriptive type. The research instrument used was the structured interview, conducted with 13 nurses of Caps I and II, belonging to the area covered by the Third Regional Health District of Rio Grande do Sul ( $3^{\mathrm{a}} \mathrm{CRS} / \mathrm{RS}$ ). From the interviews, information was obtained about the clientele of the Caps, the team's composition, and the activities the nurses carried out in the Caps. The nurses listed their activities in the routine of the Caps, and they were examined in reference to psychosocial rehabilitation within the psychiatric reform.

Keywords work; nursing; mental health. 


\section{Introdução}

O presente artigo pretende explicitar características de serviços de saúde mental como os centros de atenção psicossocial (Caps) - quanto ao tipo I ou II, atividades desenvolvidas no serviço, composição da equipe e características da clientela -, o perfil dos enfermeiros que atuam nestes serviços quanto à idade, sexo, tempo de formado, tempo de serviço, carga horária e formação em nível de pós-graduação - e as atividades desenvolvidas pelo enfermeiro no Caps, contextualizando-o no interior da reforma psiquiátrica brasileira.

Nas últimas décadas, o movimento de reforma psiquiátrica no Brasil tem tido forte influência do movimento da psiquiatria democrática italiana. A incorporação progressiva dos princípios da reforma psiquiátrica é materializada no contexto brasileiro nas portarias $n^{\circ} 189 / 1991$ e $n^{\circ} 224 / 1992$, do Ministério da Saúde, e na criação dos novos serviços. Esta regulamentação permitiu que passassem a ser remunerados novos procedimentos, como consulta individual e em grupo, por profissionais como enfermeiros, psicólogos e assistentes sociais; atendimento em oficinas terapêuticas, centros de atenção psicossocial, hospital-dia, urgência e internação em hospital geral. Regulamentou e definiu padrões mínimos para o funcionamento dos serviços de saúde mental com vistas à construção de uma rede diversificada de assistência. Em 19 de fevereiro de 2002, a portaria $n^{\circ} 336 / 2002$ classifica em ordem crescente por abrangência populacional e por complexidade os centros de atenção psicossocial, definindo a equipe mínima de profissionais e estabelecendo a clientela alvo (Brasil, 2004).

Segundo a portaria $n^{\circ} 336 / 2002$, um centro de atenção psicossocial apresenta as seguintes características:

“(...) deve prestar atendimento prioritário a pacientes com transtornos mentais severos e persistentes em sistema de atenção diária; deve funcionar de acordo com a territorialidade; deve possuir área física específica, independente de qualquer estrutura hospitalar; deve responsabilizar-se, sob coordenação do gestor local, pela organização da demanda e da rede de cuidados em saúde mental; deve possuir capacidade técnica para desempenhar o papel de regulador da porta de entrada da rede assistencial; deve constituir sua equipe de modo que esta possa supervisionar e capacitar as equipes de atenção básica, serviços e programas de saúde mental; deve realizar e manter atualizado o cadastramento dos pacientes que utilizam medicamento especiais e excepcionais. Os Caps passam a ser classificados em Caps I, Caps II, Caps III, CapsI (infância), CapsAD (álcool e drogas) e a prestar atendimento em regime intensivo (usuário freqüenta diariamente o serviço), semi-intensivo (usuário freqüenta o serviço três vezes por semana) e não intensivo (usuário freqüenta o serviço uma vez por mês)" (Brasil, 2004, p. 125). 
Foram criados, em todo país, centenas de serviços visando adequar-se às orientações da política de saúde mental brasileira. Somente na região sul do Brasil foram cadastrados 201 Caps (do total de 1.011 cadastrados no território brasileiro), desde 2002 até 2006, sendo que destes 97 são no Rio Grande do Sul, o que o configura como terceiro estado em cobertura de Caps por 100.000 habitantes. Na expansão da rede de serviços, até 2006 foram criados 475 serviços residenciais terapêuticos e 862 ambulatórios de saúde mental. Os leitos em hospitais psiquiátricos contratados pelo Sistema Único de Saúde (SUS), que em 1996 eram 72.514, diminuíram de 51.393, em 2002, para 39.567, em 2006, representando uma redução de 11.826 leitos contratados (Brasil, 2007).

O Quadro 1 traz a relação do número de leitos em hospitais psiquiátricos, do número de serviços tipo Caps e Serviço Residencial Terapêutico, segundo distribuição por ano (Brasil, 2007).

Quadro 1

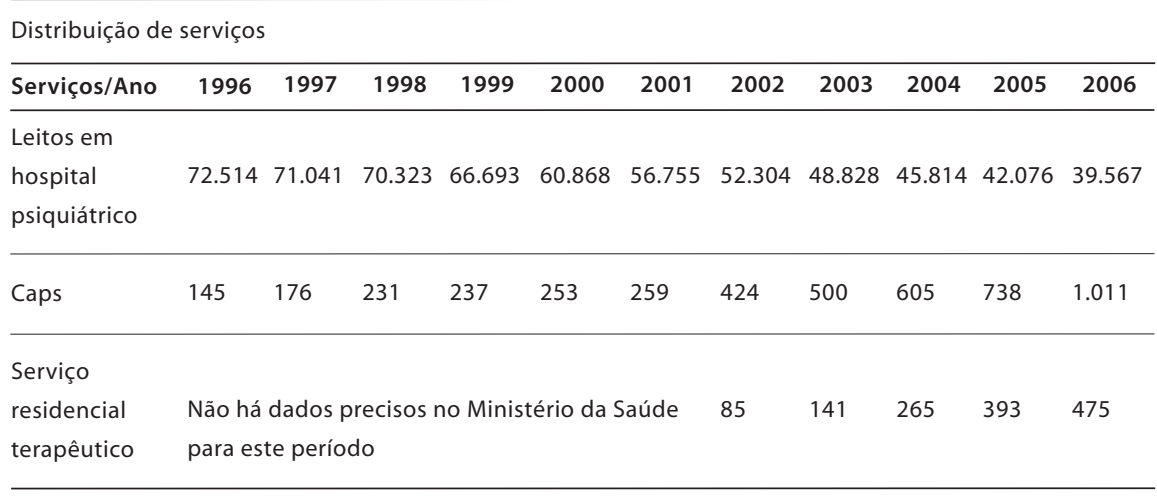

Fonte: BRASIL. Ministério da Saúde. Relatório de gestão 2003 - 2006. Brasília: MS, 2007.

Este é o contexto em que os enfermeiros de saúde mental têm trabalhado. Apesar de tais serviços coexistirem com macro-hospitais psiquiátricos, a oferta de trabalho tem sido ampliada nestes novos dispositivos de tratamento.

Neste sentido, o objetivo deste estudo consiste em identificar perfil dos enfermeiros que trabalham em Caps numa determinada região e as atividades por eles executadas e supervisionadas no cotidiano desses centros.

\section{Revisão}

No prefácio do livro Clínica da psicose: um projeto na rede pública, de autoria de Jairo Goldberg, o centro de atenção psicossocial (Caps) é definido 
como um serviço que prioriza “(...) tudo aquilo que, no momento, impede o sujeito de recuperar a força normativa de suas condutas em face do ambiente". Esta nova forma de entender o sofrimento psíquico “(...) apóia-se no princípio pragmático que diz: onde encontrar contradição na teoria, redescreva o problema. Onde encontrar contradição na prática, experimente novos modos de agir" (Costa, 1994, p. 11).

A cronificação dos casos psicóticos em psiquiatria tem sido atribuída ao curso evolutivo da patologia, somando-se a esse fato o problema da institucionalização psiquiátrica dos pacientes nos manicômios. Desse modo, considera-se que estudar outras propostas tecnológicas de intervenção nos quadros psicóticos, que sinalizam tendências a cronificação, significa ultrapassar as limitações tecnológicas existentes de intervenção no sofrimento psíquico, reestruturar o referencial de reabilitação psicossocial, redimensionar ações preventivas e de formação dos trabalhadores de saúde mental.

No contexto atual de transformação das práticas psiquiátricas, a reabilitação psicossocial redefine-se como um saber fazer que nos permite considerar o transtorno psíquico como mais um dado na história de um sujeito. Um sujeito que vive em determinado território, que estabelece relações sociais, que faz parte de uma determinada família e que é portador de um transtorno severo e persistente que tem repercussões em diferentes aspectos de sua vida.

Deste modo, o conceito de reabilitação psicossocial que se propõe inclui o transtorno psíquico do sujeito, tem como ponto de partida sua história de vida, insere-se na comunidade em que vive (considerando as possibilidades e impossibilidades de estabelecer trocas) e constitui-se em determinada sociedade a partir de políticas sociais, incluindo a oferta e as características dos serviços de saúde mental, da legislação, da cultura, da tolerância e solidariedade em relação à diferença.

Em 1992, o Psychosocial Rehabilitation Journal redefine a reabilitação em saúde mental da seguinte forma: "Significa que aquela pessoa que antes tinha medo de entrar em uma loja para pedir um sorvete de soda, hoje pode ser o gerente da loja de sorvetes" (Pratt; Gill; Barret, 1999, p. 14).

Possivelmente muitos dos usuários dos Caps não se tornem gerentes da loja de sorvetes e alcancem níveis de reabilitação psicossocial mais modestos. No entanto, é necessário se estruturar saberes e práticas de atenção em saúde mental com uma variedade de possibilidades reabilitadoras, de modo que a oferta potencial seja para que cada um, dentro de sua especificidade, possa desenvolver-se buscando a valorização da positividade do sujeito. Isto, de alguma forma, remete ao desafio de se trabalhar com os aspectos sadios do sujeito, de se focalizar o ser saudável e sua qualidade de vida, ampliando nosso campo de intervenção e cuidado para os trabalhadores de saúde mental. 
O modo psicossocial como um paradigma das práticas substitutivas ao modo asilar tem como características a interdisciplinaridade; a relação com o usuário e suas implicações subjetiva e socioculturais; a consideração deste como o participante principal de seu tratamento; o incentivo a que a família e a sociedade assumam a parte do seu compromisso na atenção e no apoio ao indivíduo em sofrimento psíquico; a ênfase à reinserção social e à recuperação da cidadania. As formas de organização no modo psicossocial baseiam-se num organograma horizontal com um fluxo em que o poder decisório se dá através de reuniões gerais e a coordenação procura administrar as ações conjuntas para fazer executar as decisões coletivas, propondo como metas de organização a participação, autogestão e interdisciplinaridade; estabelece um espaço de diálogo entre o cliente, a população, a equipe e a integralidade, partindo da noção de territorialidade (Costa-Rosa, 2000).

O Quadro 2 apresenta um paralelo entre os modos asilar e psicossocial, demarcando as contraposições entre eles.

\section{Quadro 2}

Parâmetros basilares das práticas do modo asilar e do modo psicossocial

\begin{tabular}{ll}
\hline Modo asilar & Modo psicossocial \\
\hline Ênfase no orgânico; & Considera os fatores políticos e \\
Indivíduo não participante do tratamento; & biopsicosocioculturais; \\
Indivíduo é visto como doente; & Meios: psicoterapias, laborterapias, socioterapias e \\
Intervenções centradas somente no indivíduo; & mais um conjunto de dispositivos de reintegração \\
Isolamento familiar e social; & sociocultural (destaque para as cooperativas de \\
Equipe multiprofissional, mas cuidados & trabalho); \\
fragmentados; & Indivíduo é o participante principal do seu \\
Indivíduo fragmentado (profissionais não & tratamento; \\
discutem os problemas entre si); & Indivíduo como pertencente a um grupo familliar e \\
Hegemonia médica; & social; \\
Doença: modelo médico; & Trabalhos com família e sociedade para mudanças \\
Hospital psiquiátrico: estrutura fechada; & e tratamento; \\
Organogramas piramidais e verticais com fluxo do & Diálogo, o cliente fala (interlocução); \\
ápice para a base; & Ponto de fala e de escuta da população; \\
Estratificações de poder e saber entre & Livre trânsito do usuário e da população; \\
profissionais; & Territorialização e integralidade. \\
Espaço de relação entre 'doentes' e 'sãos'; & \\
Reprodução das relações verticais do modo & \\
capitalista. &
\end{tabular}

Fonte: SOUZA, Jacqueline. Vínculos e redes sociais de indivíduos dependentes de substâncias psicoativas. Monografia de conclusão de curso de graduação em Enfermagem. Faculdade de Enfermagem e Obstetrícia da UFPel. Pelotas, 2005. 109 p.

A reabilitação psicossocial proporciona um espaço de negociação para o doente, sua família e a comunidade ali inserida. Essa negociação é difícil, pois normalmente o sujeito doente apresenta limites para contribuir e 
existe uma tendência de excluí-lo do contexto social, sob a exigência cultural da autonomia, exigência essa vista como objetivo primário da reabilitação. Para que tal autonomia ocorra, é necessário uma série de esforços por parte do sujeito e da equipe que cuida dele. Por isso a importância de levar em consideração os objetivos que queremos atingir quando nos propomos a ajudar uma pessoa psiquicamente afetada a retomar a vida normal, na família, na sociedade. A desinstitucionalização reforça a responsabilidade sob as famílias, as autoridades sanitárias e a coletividade em geral. Surge então a necessidade de acolher essas pessoas, melhorar sua qualidade de vida bem como ajudar as famílias, buscar a inserção no mundo produtivo, apoiar-se em intervenções psicoterápicas ou farmacológicas como pontos fundamentais na reabilitação psicossocial do indivíduo (Saraceno, 2001).

A formação dos trabalhadores de saúde mental 4 consiste num aspecto que não é possível deixar de assinalar. Considerando que a lei $\mathrm{n}^{\circ} 10.216$, que trata da reforma psiquiátrica brasileira, foi sancionada em abril de 2001, após 12 anos de tramitação, considerando ainda que esta indica a substituição progressiva do modelo assistencial hospitalocêntrico, acentuase a necessidade de inclusão de conteúdos pertinentes a esta realidade nos currículos dos cursos da área de saúde, reorientando seus projetos pedagógicos (Brasil, 2004).

As tecnologias em saúde podem se configurar em materiais concretos como medicamentos, materiais permanentes e de consumo, saberes estruturados para compreender o processo saúde-doença (o sofrimento psíquico) e/ou as relações, vínculos, interações e comunicações que ocorrem com a equipe e com o usuário dos serviços de saúde mental e seus familiares Merhy, 1997).

\section{Metodologia}

Trata-se de um estudo qualitativo, com um tipo de desenho descritivo, onde se incluem os Caps I e II cadastrados pelo Ministério da Saúde, conforme a portaria $\mathrm{n}^{\circ} 336 / 2002$, que fazem parte da área de abrangência da Terceira Coordenadoria Regional de Saúde do Rio Grande do Sul ( $3^{\text {a }}$ CRS/RS). Foi submetido à apreciação e aprovado no Comitê de Ética em Pesquisa da Faculdade de Medicina da Universidade Federal de Pelotas. Solicitou-se o consentimento livre e esclarecido dos sujeitos da pesquisa, respeitando-se todos os preceitos ético-legais que regem a pesquisa em seres humanos, conforme o preconizado pela resolução $n^{\circ}$ 196/96, do Conselho Nacional de Saúde, Ministério da Saúde, e pelo Código de Ética dos Profissionais de Enfermagem. 
Inicialmente, fizemos um levantamento bibliográfico da produção científica da enfermagem psiquiátrica na base Lilacs, em mais de mil resumos de artigos e 109 artigos publicados entre 1980 e 2001 em periódicos de arbitragem e analisados na íntegra. O processo analítico da temática saberes e estudos teóricos em saúde mental na produção científica dos enfermeiros foi reagrupado nas seguintes subtemáticas: estudos teóricos com enfoque histórico (foco no modelo asilar e foco na transformação na assistência de enfermagem psiquiátrica), participação da família no processo saúde-doença do paciente, compreensão do homem - indivíduo portador de sofrimento psíquico, estigma, utilização dos resultados da pesquisa de enfermagem psiquiátrica, reformulação do ensino, instrumentos de pesquisa, trabalho de enfermagem. Pudemos constatar os avanços da produção de saberes, na assistência e no ensino de enfermagem quanto ao desenvolvimento de uma compreensão dos transtornos psíquicos e suas expressões, com vistas a se trabalhar com as limitações impostas pelos mesmos, assumindo o desafio de prestar um cuidado voltado à reabilitação psicossocial (Kantorski et al., 2004).

Os instrumentos utilizados foram: análise documental e entrevistas. A análise documental recolheu junto à Coordenadoria Regional de Saúde e os Caps documentos como: projeto terapêutico, guia de saúde mental estadual e relatórios descritivos dos serviços que permitiram uma aproximação com a realidade estudada. A entrevista estruturada (ver roteiro no Anexo) foi realizada com os enfermeiros dos Caps I e II, que pertencem à área de abrangência da $3^{a}$ CRS/RS, na qual foram apreendidas informações sobre características da clientela atendida no serviço, composição da equipe, atividades realizadas e ações desenvolvidas pelo enfermeiro no Caps. As entrevistas foram gravadas e transcritas na íntegra. Os 13 enfermeiros dos 13 Caps (1 Caps AD, 4 Caps I e 8 Caps II) compuseram o grupo social do estudo.

Os dados foram agrupados a partir do Software NVivo 2.0 para análise de dados qualitativos e sistematizados em quadros que retratam a síntese do perfil dos serviços, dos enfermeiros e das práticas desenvolvidas nestes dispositivos.

Para dar conta do objeto de estudo propõe-se a utilização do referencial do materialismo histórico e dialético. As concepções adotadas dizem respeito ao entendimento acerca do homem enquanto ser social e as diversas formas de se conformar e de resistir ao conjunto de circunstâncias e projetos sociais. Deste modo, o processo de reforma psiquiátrica é visto como uma possibilidade de construção de sujeitos sociais que, aglutinados em torno de um projeto, resiste a um corpo de manicômios simbólicos que se concretizam nos preconceitos, nas instituições, enfim, em práticas hegemônicas acerca da loucura. 
Ao longo de milhões de anos, o trabalho tem sido o meio pelo qual o homem se diferencia de sua condição animal e se humaniza. Assim, é necessário se pensar o ser humano sem desvinculá-lo de sua atividade material transformadora. $\mathrm{O}$ modo como as práticas de enfermagem psiquiátrica e saúde mental tem se configurado historicamente retrata como seres humanos se inserem no modo de produção vigente, transformando a natureza, outros homens e a si mesmos nas atividades que desenvolvem.

O motor da dialética materialista é o trabalho material propriamente dito, ou seja: “(...) o trabalho como relação dos homens com a natureza, para negar as coisas naturais enquanto naturais, transformando-as em coisas humanizadas ou culturais, produtos do trabalho" (Chauí, 1991, p. 53).

O homem, ao transformar a natureza de acordo com um projeto construído conscientemente, ou seja, o trabalho dotado de finalidade, transforma a si mesmo, relativizando assim a sua soberania sobre a natureza. A relativização da referida soberania decorre de fatores externos aos homens singulares e a seus respectivos interesses. Os fatores externos consistem nas circunstâncias materiais e coletivas, em que há oposição de interesses que determinam o modo como se configura a produção. É pertinente, deste modo, relativizar a autonomia e o poder de transformação dos diferentes sujeitos que, concretamente, mesmo que conscientes da necessidade de transformação, por exemplo, da assistência psiquiátrica, mesmo desencadeando processos de mudanças vão encontrar muitas barreiras impeditivas. As barreiras consistem em mecanismos do sistema vigente, que concorrem para manter a hegemonia da classe dominante, materializadas em formas específicas como, por exemplo, olhar o louco como improdutivo, logo, configurando-se em mais um grupo social que, dentro do sistema capitalista, vem compor o grupo dos excluídos. Institui-se, assim, uma lógica de sociabilidade perversa que, quando abarca os diferentes, o faz baseada em sua capacidade de consumo e não em mecanismos de solidariedade.

A importância do trabalho na vida do homem encontra-se destacada, neste estudo, a partir da discussão de cinco dimensões essenciais, ancoradas no materialismo histórico e dialético: o homem, ao produzir a sua própria existência, produz a si mesmo; a práxis do trabalho revela uma relação metabólica entre o homem e a natureza; o trabalho gera relações sociais; o trabalho é fundamental para a criação da identidade do homem; o trabalho enquanto práxis propriamente humana é a maneira pela qual o homem transcende-se no espaço e no tempo, pois através do trabalho o homem imprime no mundo material um conhecimento acumulado ao longo da história, constituindo-se assim produtor da própria história (Kantorski, 1997).

A sociedade em que vivemos é produzida por homens concretos que, por sua vez, são, em parte, determinados social e historicamente pela produção da vida material. Assim, 
"A consciência nunca pode ser mais que o ser consciente; e o ser dos homens é o seu processo de vida real (...) são os homens que, desenvolvendo sua produção material e suas relações materiais, transformam, com a realidade que lhes é própria, seu pensamento e também os produtos do seu pensamento" (Marx; Engels, 1989, p. 20).

\section{Resultados e discussão}

Temos concentrado nossos estudos nos processos de mudança que vêm ocorrendo na atenção psiquiátrica, ressaltando a importância da incorporação deles à formação de enfermeiros.

Segundo o Guia de saúde mental (2001), os seguintes municípios compõem a $3^{\text {a }} \mathrm{CRS} / \mathrm{RS}$ : Amaral Ferrador, Arroio do Padre, Arroio Grande, Canguçu, Capão do Leão, Cerrito, Chuí, Cristal, Herval, Jaguarão, Morro Redondo, Pedras Altas, Pedro Osório, Pelotas, Pinheiro Machado, Piratini, Rio Grande, Santa Vitória do Palmar, Santana da Boa Vista, São José do Norte, São Lourenço do Sul, Tavares e Turuçu (Brasil, 2001).

Entre estes municípios, possuem serviços de saúde mental na $3^{\text {a }}$ CRS: Canguçu (Caps - Casa de Saúde Mental); Capão do Leão (Casa Vida); Jaguarão (Caps - Sítio Renascer, Ambulatório de Saúde Mental, Santa Casa de Caridade de Jaguarão - leitos SUS: 6); Pedras Altas (Unidade de Saúde); Pelotas (Caps Baronesa, Caps Escola, Caps Castelo, Caps Fragata, Caps Zona Norte, Caps Porto, Ambulatório Central para População Rural, Sociedade Portuguesa de Beneficência - leitos SUS: 1, Sanatório Espírita de Pelotas leitos SUS: 179); Rio Grande (Caps Conviver, Hospital de Ensino Dr. Miguel Correa Junior - leitos SUS: 5; Hospital Psiquiátrico Vicença Maria da Fontoura - leitos SUS: 100); Santa Vitória do Palmar (Caps - Casa Nova Vida); São José do Norte (Unidade de Saúde, Associação do Hospital e Maternidade de São Francisco - leitos SUS: 7), São Lourenço do Sul (Caps Nossa Casa, Santa Casa de Misericórdia de São Lourenço do Sul - leitos SUS: 7) (Brasil, 2001).

Apresentamos a seguir o Quadro 3, com o perfil dos Caps estudados, a equipe, as características da clientela atendida e as atividades desenvolvidas. 
Quadro 3

\begin{tabular}{|c|c|c|c|}
\hline Tipo de Caps & Atividades desenvolvidas & Composição da equipe & Característica da clientela \\
\hline Caps I & $\begin{array}{l}\text { Acolhimento, oficinas, } \\
\text { grupos. }\end{array}$ & $\begin{array}{l}\text { Médico; psicóloga; } \\
\text { assistente social; artista } \\
\text { plástico; auxiliares de } \\
\text { enfermagem; enfermeiro; } \\
\text { cozinheira; servente. }\end{array}$ & Adultos e adolescentes. \\
\hline Caps I & Grupos. & $\begin{array}{l}\text { Psiquiatra; psicólogo; } \\
\text { enfermeira; auxiliar de } \\
\text { enfermagem; assistente } \\
\text { social; auxiliar de } \\
\text { higienização; recepção; } \\
\text { merendeira. }\end{array}$ & $\begin{array}{l}\text { Dependente químico; } \\
\text { distúrbios psiquiátricos; } \\
\text { adultos e adolescentes. }\end{array}$ \\
\hline Caps I & Grupos e oficinas. & $\begin{array}{l}\text { Médico clínico; } \\
\text { psiquiatra; enfermeiro; } \\
\text { auxiliar de enfermagem; } \\
\text { psicólogo; assistente. } \\
\text { social; artesão; serviço } \\
\text { geral; administrativo; } \\
\text { terapeuta ocupacional. }\end{array}$ & $\begin{array}{l}\text { Adultos, jovens, idosos e } \\
\text { crianças. }\end{array}$ \\
\hline Caps I & Grupos e oficinas. & $\begin{array}{l}\text { Enfermeiro; médico } \\
\text { clínico; psiquiatra; } \\
\text { assistente social; } \\
\text { psicólogo; farmacêutico; } \\
\text { auxiliar administrativo; } \\
\text { serviço geral; } \\
\text { merendeira; educação } \\
\text { física; terapeuta } \\
\text { ocupacional. }\end{array}$ & Adultos. \\
\hline Caps II & Não respondeu. & $\begin{array}{l}\text { Profissional de artes; } \\
\text { música; educação física; } \\
\text { psicólogo; psiquiatra; } \\
\text { enfermeiro; cozinheira; } \\
\text { guarda; auxiliar de } \\
\text { higienização; burocrata; } \\
\text { educadora social; } \\
\text { assistente social; } \\
\text { auxiliares de } \\
\text { enfermagem. }\end{array}$ & Adultos e alguns adolescentes. \\
\hline
\end{tabular}


Continuação - Quadro 3

\begin{tabular}{|c|c|c|c|}
\hline Tipo de Caps & Atividades desenvolvidas & Composição da equipe & Característica da clientela \\
\hline Caps II & Grupos e oficinas. & $\begin{array}{l}\text { Assistente social; } \\
\text { enfermeiro; auxiliar de } \\
\text { enfermagem; psicólogo; } \\
\text { psiquiatra; professora de } \\
\text { música; artista plástico; } \\
\text { cozinheira; profissional } \\
\text { da higiene; profissional } \\
\text { de educação física. }\end{array}$ & $\begin{array}{l}\text { Adultos portadores de } \\
\text { transtornos psíquicos. }\end{array}$ \\
\hline Caps II & Grupos e oficinas. & $\begin{array}{l}\text { Psicólogo; psiquiatra; } \\
\text { auxiliar de enfermagem; } \\
\text { enfermeira; profissional } \\
\text { de artes; profissional de } \\
\text { música; de educação } \\
\text { física; de artes. }\end{array}$ & $\begin{array}{l}\text { Adultos maiores de } \\
18 \text { anos. }\end{array}$ \\
\hline Caps II & $\begin{array}{l}\text { Grupo de usuários; grupo de } \\
\text { familiares; grupo vocal. }\end{array}$ & $\begin{array}{l}\text { Psiquiatra; enfermeiro; } \\
\text { auxiliar de enfermagem; } \\
\text { auxiliar administrativo; } \\
\text { merendeira; profissional } \\
\text { da educação das artes; } \\
\text { profissional de nível } \\
\text { superior da música; } \\
\text { profissional de educação } \\
\text { física. }\end{array}$ & Adultos. \\
\hline Caps II & $\begin{array}{l}\text { Grupos de medicação; } \\
\text { grupos de família. }\end{array}$ & $\begin{array}{l}\text { Merendeira; auxiliar } \\
\text { administrativo; médico } \\
\text { clínico; psiquiatra; } \\
\text { enfermeiro; auxiliar de } \\
\text { enfermagem; psicólogo; } \\
\text { assistente social. }\end{array}$ & Adultos. \\
\hline Caps II & Grupos. & $\begin{array}{l}\text { Psiquiatra; enfermeiras; } \\
\text { psicólogo; assistente } \\
\text { social; auxiliar de } \\
\text { enfermagem; } \\
\text { merendeira; artista } \\
\text { plástico; educação física. }\end{array}$ & Adultos. \\
\hline
\end{tabular}




\begin{tabular}{|c|c|c|c|}
\hline Tipo de Caps & Atividades desenvolvidas & Composição da equipe & Característica da clientela \\
\hline Caps II & Grupos e oficinas. & $\begin{array}{l}\text { Psiquiatra; enfermeiro; } \\
\text { auxiliar de enfermagem; } \\
\text { psicólogo; assistente } \\
\text { social; artista plástica; } \\
\text { educação física; música; } \\
\text { auxiliar administrativo. }\end{array}$ & A partir dos 18 anos. \\
\hline Caps II & Grupos e oficinas. & $\begin{array}{l}\text { Psicólogo; psiquiatra; } \\
\text { enfermeiro; assistente } \\
\text { social; auxiliar de } \\
\text { enfermagem; burocrata; } \\
\text { merendeira; serviço } \\
\text { geral. }\end{array}$ & Adultos. \\
\hline Caps AD & $\begin{array}{l}\text { Grupos e oficinas; } \\
\text { desintoxicação; grupo de } \\
\text { promoção de abstinência; } \\
\text { grupo de jovens; grupo de } \\
\text { outras drogas; oficina de } \\
\text { artesanato; oficina de } \\
\text { música; oficina de auto- } \\
\text { cuidado; oficina de educação } \\
\text { física; oficina de jardinagem; } \\
\text { marcenaria; oficina de } \\
\text { pintura }\end{array}$ & $\begin{array}{l}\text { Enfermeiro; técnico de } \\
\text { enfermagem; auxiliar de } \\
\text { enfermagem; psicólogas; } \\
\text { assistentes sociais; } \\
\text { psiquiatras; burocrata; } \\
\text { profissionais de artes; } \\
\text { música; educação física. }\end{array}$ & $\begin{array}{l}\text { Usuários de álcool e drogas, a } \\
\text { partir dos } 14 \text { anos. }\end{array}$ \\
\hline
\end{tabular}

A concepção do trabalho em equipe interdisciplinar introduzida com as mudanças preconizadas, as noções de acolhimento e de escuta terapêutica, os planos terapêuticos individualizados, a reabilitação psicossocial, entre outros, têm exigido uma requalificação e expansão dos papéis profissionais do enfermeiro na prestação do cuidado em saúde mental.

No Quadro 4, apresentamos um perfil dos enfermeiros dos Caps estudados. Observamos que a faixa etária em que se encontram $66 \%$ dos enfermeiros dos Caps estudados concentra-se entre 25 e 40 anos; $86 \%$ são do sexo feminino; $60 \%$ têm mais de cinco anos de graduado e 73,3\% têm no máximo dois anos de trabalho em Caps; $20 \%$ têm pós-graduação. 


\begin{tabular}{|c|c|c|c|c|c|c|c|}
\hline \multicolumn{8}{|c|}{ Perfil dos enfermeiros } \\
\hline Enfermeiros & $\begin{array}{l}\text { Tipo de } \\
\text { Caps }\end{array}$ & Idade & Sexo & $\begin{array}{l}\text { Tempo de } \\
\text { formado }\end{array}$ & $\begin{array}{l}\text { Tempo de } \\
\text { serviço }\end{array}$ & $\begin{array}{c}\text { Carga } \\
\text { horária }\end{array}$ & Pós-graduação \\
\hline A & Caps AD & 37 anos & Feminino & 15 anos & 6 meses & 20 horas & Não \\
\hline & & & & & & & Educação \\
\hline B & Caps II & 39 anos & Feminino & 10 anos & 3 anos & 20 horas & $\begin{array}{c}\text { Continuada e } \\
\text { docência }\end{array}$ \\
\hline$C$ & Caps II & 26 anos & Feminino & 1 ano & 1 ano e 6 meses & 20 horas & Não \\
\hline D & Caps I & 26 anos & Masculino & 8 meses & 8 meses & 44 horas & Não \\
\hline $\mathrm{E}$ & Caps I & 26 anos & Feminino & 4 anos & 4 meses & 10 horas & Não \\
\hline $\mathrm{F}$ & Caps II & 27 anos & Feminino & 7 anos & 1 ano & 20 horas & Não \\
\hline G & Caps II & 33 anos & Feminino & 6 anos & 1 ano e 5 meses & 20 horas & Não \\
\hline $\mathrm{H}$ & Caps II & 47 anos & Feminino & 21 anos & 1 ano e 1 mês & 20 horas & Não \\
\hline 1 & Caps II & 45 anos & Feminino & 11 anos & 2 anos e 9 meses & 40 horas & Não \\
\hline J & Caps II & 32 anos & Feminino & 1 ano & 6 meses & 20 horas & Não \\
\hline $\mathrm{K}$ & Caps II & 47 anos & Feminino & 18 anos & 1 ano & 30 horas & Não \\
\hline & & & & & & & $\begin{array}{l}\text { Residência na } \\
\text { Clínica Pinel e }\end{array}$ \\
\hline L & Caps I & 44 anos & Feminino & 21 anos & 9 anos & 30 horas & $\begin{array}{c}\text { Especialização em } \\
\text { Enfermagem } \\
\text { Psiquiátrica }\end{array}$ \\
\hline M & Caps II & 25 anos & Feminino & 2 anos & 9 meses & 20 horas & $\begin{array}{l}\text { Sim. Cursando } \\
\text { Especialização }\end{array}$ \\
\hline $\mathrm{N}$ & Caps II & 55 anos & Masculino & 11 anos & 1 ano & 30 horas & Não \\
\hline $\mathrm{O}$ & Caps I & 34 anos & Feminino & 5 anos & 1 ano & 32 horas & Não \\
\hline
\end{tabular}

As práticas terapêuticas que visam à reabilitação do indivíduo em sofrimento psíquico resgatam um trabalho com características coletivas que prevê intervenções multidisciplinares que incluem a participação da família e do indivíduo. Algumas destas práticas podem ser constatadas no quadro que descreve as atividades desenvolvidas pelo enfermeiro no Caps. 
O Quadro 5, além de reafirmar as características do processo de trabalho mais coletivas com relação ao objeto de trabalho, aos instrumentos, às práticas, aos espaços e à finalidade, evidencia uma perspectiva multidisciplinar. Os espaços coletivos de grupos, oficinas, assembléias, reuniões de equipe, atividades de lazer, núcleo familiar, entre outros, apontam para um processo de trabalho organizado a partir de uma lógica dos múltiplos modos de saber fazer e suas possíveis interconexões.

\section{Quadro 5}

Práticas do enfermeiro no Caps

\section{Práticas}

\begin{tabular}{|c|c|}
\hline Acolhimento & Desintoxicação e avaliação do estado do paciente \\
\hline Conversar & Avaliação física e psíquica \\
\hline Atendimento a familiares & Atividades na recepção \\
\hline Grupo de medicação & Atendimento de enfermagem individual \\
\hline Interação e vínculo com os pacientes & $\begin{array}{l}\text { Preparo e supervisão da administração de } \\
\text { medicamentos }\end{array}$ \\
\hline Acompanhamento do lanche e almoço & Registro em prontuário \\
\hline $\begin{array}{l}\text { Coordenação de oficinas de: costura, marcenaria, } \\
\text { tricô, higiene e cuidado pessoal }\end{array}$ & Atividades administrativas \\
\hline Assembléia - coordenação, participação. & $\begin{array}{l}\text { Supervisão e capacitação dos auxiliares e técnicos } \\
\text { de enfermagem }\end{array}$ \\
\hline Intervenções multidisciplinares & $\begin{array}{l}\text { Encaminhamento para internação s/n e } \\
\text { encaminhamento para atenção básica. }\end{array}$ \\
\hline \multicolumn{2}{|l|}{ Reuniões de equipe } \\
\hline \multicolumn{2}{|l|}{ Acompanhamento a passeios e festas } \\
\hline \multicolumn{2}{|l|}{$\begin{array}{l}\text { Fazer atividade de lazer junto com usuários } \\
\text { (como assistir aos jogos olímpicos na televisão) }\end{array}$} \\
\hline \multicolumn{2}{|l|}{ Elo entre a Unidade Básica de Saúde e o Caps } \\
\hline Coordenação do serviço & \\
\hline
\end{tabular}


Podemos identificar, através dos dados obtidos, um processo de trabalho nos Caps com características coletivas com relação ao objeto de trabalho que deixa de ser centralmente a doença e mesmo o corpo e a mente do indivíduo para constituir-se enquanto um sujeito de desejos, contradições e contextualizado em determinado grupo familiar e social.

Em relação às práticas de trabalho que passam a se utilizar das oficinas, grupos, assembléias, que, apesar de englobar as práticas individuais como psicoterapias, manejos, psicofármacos, as toma em relação ao todo do sujeito enquanto ser social, numa perspectiva ampliada incluindo a atenção à família, incorporando atividades de lazer e interfaces com a atenção básica. A perspectiva de trabalho para o enfermeiro insere-se em uma prática ampliada que extrapola significativamente os recursos tradicionais (como a comunicação e o relacionamento terapêutico, o atendimento individual, a administração de medicamentos, entre outros) utilizados no trabalho de enfermagem enquanto saberes que subsidiavam práticas manicomiais (Kantorski et al., 2004).

Estes saberes são históricos e, portanto, se contextualizam no Caps no interior do modo psicossocial. A consideração de que a loucura não é um fenômeno exclusivamente individual leva à inclusão da família e do grupo ampliado, requerendo como meio de trabalho a equipe interprofissional visando uma ação integral ao sujeito (Costa-Rosa, 2000).

Com relação aos instrumentos como técnicas grupais, entrevista, acolhimento, cuidados com a medicação, comunicação terapêutica, técnicas expressivas, artísticas, entre outras, destacamos que o enfermeiro lança mão do saber acumulado na profissão, porém existe uma certa plasticidade no seu fazer que é exigida no cotidiano do trabalho no Caps. A oferta de múltiplas oficinas, o intercâmbio entre os profissionais, o cuidado à família, o trânsito entre atividades de cuidado, administração e mobilidade de cenários, como o elo com a atenção básica requerem flexibilização no fazer do enfermeiro.

Ocorrem mudanças também na finalidade do processo de trabalho do enfermeiro, quando o espaço é o Caps. Pois esta passa a se constituir na reabilitação psicossocial que inclui a reinserção do sujeito nas atividades diárias da casa, no mundo do trabalho (seja através de um trabalho protegido ou numa oficina) e nos espaços comunitários (ricos de relações, de trocas, de posicionamentos). Este desafio é assumido cotidianamente nas atividades de cuidado como no acompanhamento do almoço, nas festas e atividades sociais, nas oficinas e grupos enquanto espaços terapêuticos e de socialização entre outros.

Ao se retomar Marx para pensar as contradições do trabalho alienado no capitalismo, constatamos que as condições para que o trabalho possa se constituir como vetor de existencialização são muito reduzidas e até 
inexistentes. O desafio dos espaços de expressão e produção coletiva consiste em estabelecer novas e melhores conexões entre a produção desejante e a produção da vida material, transformando-se em espaços de construção de territórios existenciais (Rauter, 2000).

A institucionalização de saberes e sua organização em práticas ocorre mediante a conformação de núcleos e de campos. O núcleo consiste nos conhecimentos e na conformação de um determinado padrão das práticas com a produção de valores de uso destes, demarcando a identidade de uma área de saber e de sua prática profissional; e já o campo consiste num espaço de limites imprecisos em que cada disciplina e profissão busca em outras o apoio para cumprir suas tarefas teóricas e práticas (Campos, 2000).

O núcleo de cada profissão, no caso também aquele específico da profissão do enfermeiro, é preservado e ampliado nos serviços substitutivos, as interconexões objetivando-se no campo da reabilitação psicossocial.

Ressaltamos uma realidade em movimento em que se introduzem tecnologias e instrumentos de abordagem e intervenção no sofrimento psíquico, construídos ou redimensionados no interior do processo de reforma psiquiátrica, que poderão ser incorporados ao cotidiano do trabalho e à formação dos trabalhadores de saúde mental, os enfermeiros.

\section{Conclusão}

No contexto de implantação do modo psicossocial, que orienta o trabalho dos enfermeiros nos Caps, define-se um 'saber fazer' dotado de relativa autonomia pertinente ao processo criativo que se materializa no momento do ato do trabalho em saúde.

As opções teórico-metodológicas e ideológicas adotadas na prática dos serviços e do ensino podem favorecer a conformação de saberes e práticas manicomiais e de transformação destes. Tais opções devem possibilitar a reflexão crítica acerca da definição do objeto de trabalho - o indivíduo portador de sofrimento psíquico, a família, os grupos - e das tecnologias adotadas com vistas a redimensionar o cuidado em saúde mental.

No presente estudo os enfermeiros dos centros de atenção psicossocial estudados destacaram em sua prática cotidiana atividades como: acolhimento; atendimento a familiares; grupo de medicação; interação e vínculo com os pacientes; acompanhamento de refeições; participação e coordenação compartilhada de oficinas; coordenação e participação da assembléia; intervenções multidisciplinares; reuniões de equipe; acompanhamento do usuário atividades de lazer; promoção do elo entre a atenção básica e o serviço; coordenação; avaliação de enfermagem; atendimento individual; preparo e supervisão da administração de medicamentos; registro em 
prontuário; atividades administrativas; supervisão e capacitação dos auxiliares e técnicos de enfermagem.

\section{Anexo}

\section{Roteiro de Entrevista}

\section{Dados de identificação do enfermeiro:}

Nome:

Sexo:

Idade:

Tempo de formado (meses/anos):

Tempo que atua no serviço (meses/anos):

Carga horária efetivamente realizada em função do Caps:

Possui outro emprego (em caso afirmativo, explicitar função e local):

Realizou cursos de aperfeiçoamento/pós-graduação na área da saúde mental? Em caso de resposta afirmativa, citar nome do curso, instituição promotora, ano em que realizou o curso e enfoque central da formação.

\section{Caracterização do serviço:}

Nome do serviço:

Município:

Data de início do funcionamento do serviço:

Data em que foi cadastrado como Caps (especificar se foi cadastrado como Caps I ou II):

População de referência:

Horário de funcionamento do serviço:

Características da clientela atendida no serviço (adulto, crianças, faixa etária, tipos de transtornos psíquicos mais atendidos no serviço, verificar se existem dados sistematizados de prevalência dos transtornos):

Composição da equipe:

\section{Questões:}

1. Que tipo de atividades você desenvolve no seu dia a dia no Caps? Descreva-as.

2. Descreva um dia típico de seu trabalho como enfermeiro no Caps. 


\section{Notas}

1 Professora adjunta da Faculdade de Enfermagem e Obstetrícia da Universidade Federal de Pelotas (UFPel), Pelotas, Rio Grande do Sul, Brasil. Doutora em Enfermagem pela Escola de Enfermagem de Ribeirão Preto, da Universidade de São Paulo (EERP/USP). $<$ kantorski@uol.com.br>

Correspondência: Universidade Federal de Pelotas, Departamento de Enfermagem, Faculdade de Enfermagem e Obstetrícia, Avenida Duque de Caxias, 250, Fragata, Pelotas, Rio Grande do Sul, Brasil, CEP 96030-002.

2 Graduada em Enfermagem e Obstetrícia pela Universidade Federal de Pelotas (UFPel), Pelotas, Rio Grande do Sul, Brasil. Mestranda em Enfermagem pela Universidade Federal do Rio Grande do Sul (UFRGS). <fbmielke@gmail.com>

3 Graduado em Enfermagem e Obstetrícia pela Universidade Federal de Pelotas (UFPel), Pelotas, Rio Grande do Sul, Brasil. Mestrando em Enfermagem pela Universidade Federal do Rio Grande do Sul (UFRGS). <sidneienf@yahoo.com.br>

${ }^{4}$ A dissonância entre ensino e processo da reforma psiquiátrica no Brasil, no campo da formação em enfermagem, foi abordada por Kantorski e Silva (2001), tendo as autoras enfatizado que as disciplinas de graduação da área enfocavam o normal e o patológico no transcorrer do ciclo vital, sofrendo influências do discurso da psiquiatria preventiva, da psicanálise, predominantemente voltadas para o enfoque psicodinâmico. Os estágios na área continuavam sendo realizados nos hospitais psiquiátricos, enfatizando as psicopatologias e acentuando a manutenção do modelo manicomial.

\section{Referências}

BRASIL. Ministério da Saúde. Secretaria Executiva. Secretaria de Atenção à Saúde. Legislação em saúde mental: 1990-2004. 5. ed. ampl. Inclui portarias $n^{\circ}$ s 189/1991; 224/1992; 336/2002. Brasília: MS, 2004. $340 \mathrm{p}$.

BRASIL. Ministério da Saúde. Relatório de gestão 2003-2006. Brasília: MS, 2007.

CAMPOS, Gastão Wagner de Sousa. Saúde pública e saúde coletiva: campo e núcleo de saberes e práticas. Ciência e Saúde Coletiva, Rio de Janeiro, v. 5, n. 2, p. 219-230, 2000.

CHAUÍ, Marilena. O que é ideologia. Coleção Primeiros Passos 13. 34. ed. São Paulo: Brasiliense, 1991.
COSTA, Jurandir Freire. Apresentação. In: Clínica da psicose: um projeto na rede pública. Rio de Janeiro: Te Corá, 1994. p. 9-17.

COSTA-ROSA, Abílio. O modo psicossocial: um paradigma das práticas substitutivas ao modo asilar. In: AMARANTE, Paulo (Org.). Ensaios: subjetividade, saúde mental, sociedade. Coleção Loucura \& Civilização. Rio de Janeiro, editora Fiocruz, 2000. p. 141-168.

KANTORSKI, Luciane Prado. As transformações no mundo do trabalho e a questão da saúde. Revista Latino-Americana de Enfermagem. Ribeirão Preto, v. 5, n. 2, p. 5-15, 1997. 
KANTORSKI, Luciane Prado; SILVA, Graciette Borges da. Ensino de enfermagem e reforma psiquiátrica. Pelotas: Editora da Universidade Federal de Pelotas, 2001. 241 p.

KANTORSKI, Luciane Prado et al. Saberes e estudos teóricos em enfermagem psiquiátrica e saúde mental. Revista Gaúcha de Enfermagem, Porto Alegre, v. 25, n. 3, p. 408-419, 2004.

MARX, Karl; ENGELS, Friedrich. A ideologia alemã. São Paulo, Martins Fontes, 1989.

MERHY, Emerson Elias. Em busca do tempo perdido: a micropolítica do trabalho vivo em saúde. In: MERHY, Emerson Elias; ONOCKO, Rosana (Orgs.). Agir em saúde: um desafio para o público. São Paulo, Hucitec, 1997. p. 71-112.

PRATT, Carlos; GILL, Kenneth; BARRET, Nora. Psychiatric Rehabilitation. London: Academic Express, 1999. 296 p.
RAUTER, Cristina. Oficinas para quê? - uma proposta ético-estético-política para oficinas terapêuticas. In: AMARANTE, Paulo (Org.). Ensaios: subjetividade, saúde mental, sociedade. Rio de Janeiro, editora Fiocruz, 2000. p. 267-277.

RIO GRANDE DO SUL. Guia de Saúde Mental. Porto Alegre: RS, 2001. 146 p.

SARACENO, Benedetto. Libertando identidades: da reabilitação psicossocial à cidadania possível. 2. ed. Rio de Janeiro: Te Corá, 2001.

SOUZA, Jacqueline. Vinculos e redes sociais de individuos dependentes de substâncias psicoativas. Monografia de conclusão de curso de graduação em Enfermagem. Faculdade de Enfermagem e Obstetrícia da UFPel. Pelotas, 2005. 109 p.

Recebido em 01/03/2006

Aprovado em 27/12/2007 